\title{
Kinetics and mechanisms of the catalytic thermal cracking of asphaltenes adsorbed on supported nanoparticles
}

\author{
Tatiana Montoya $^{1} \cdot$ Blanca L. Argel ${ }^{2}$. \\ Nashaat N. Nassar ${ }^{1}$ Camilo A. Franco ${ }^{2,3}$. \\ Farid B. Cortés ${ }^{2,3}$
}

Received: 28 September 2015/Published online: 1 July 2016

(c) The Author(s) 2016. This article is published with open access at Springerlink.com

\begin{abstract}
The production of heavy and extra-heavy oil is challenging because of the rheological properties that crude oil presents due to its high asphaltene content. The upgrading and recovery processes of these unconventional oils are typically water and energy intensive, which makes such processes costly and environmentally unfriendly. Nanoparticle catalysts could be used to enhance the upgrading and recovery of heavy oil under both in situ and ex situ conditions. In this study, the effect of the Ni-Pd nanocatalysts supported on fumed silica nanoparticles on post-adsorption catalytic thermal cracking of $n-C_{7}$ asphaltenes was investigated using a thermogravimetric analyzer coupled with FTIR. The performance of catalytic thermal cracking of $n-\mathrm{C}_{7}$ asphaltenes in the presence of $\mathrm{NiO}$ and $\mathrm{PdO}$ supported on fumed silica nanoparticles was better than on the fumed silica support alone. For a fixed amount of adsorbed $n-\mathrm{C}_{7}$ asphaltenes $\left(0.2 \mathrm{mg} / \mathrm{m}^{2}\right)$, bimetallic nanoparticles showed
\end{abstract}

Nashaat N. Nassar

nassar@ucalgary.ca

$\triangle$ Camilo A. Franco

caafrancoar@unal.edu.co

Farid B. Cortés

fbcortes@unal.edu.co

1 Department of Chemical and Petroleum Engineering, University of Calgary, 2500 University Drive NW, Calgary, $\mathrm{AB}$, Canada

2 Grupo de Investigación Fenómenos de Superficie-Michael Polanyi, Facultad de Minas, Universidad Nacional de Colombia Sede Medellín, Medellín, Colombia

3 Grupo de Investigación en Yacimientos de Hidrocarburos, Facultad de Minas, Universidad Nacional de Colombia Sede Medellín, Kra 80 No. 65-223, Medellín, Colombia

Edited by Xiu-Qin Zhu better catalytic behavior than monometallic nanoparticles, confirming their synergistic effects. The corrected OzawaFlynn-Wall equation (OFW) was used to estimate the effective activation energies of the catalytic process. The mechanism function, kinetic parameters, and transition state thermodynamic functions for the thermal cracking process of $n-\mathrm{C}_{7}$ asphaltenes in the presence and absence of nanoparticles are investigated.

Keywords Catalytic thermal cracking - Adsorption . Nanoparticles $\cdot \mathrm{SHS} \cdot n-\mathrm{C}_{7}$ asphaltene

\section{Introduction}

Currently, fossil fuels supply approximately $82 \%$ of the world's energy demand (Ghannam et al. 2012). The growing demand for crude oil worldwide requires the exploitation of heavy and extra-heavy crude oil deposits, which are approximately of the same order as conventional crude oil according to the International Energy Agency (Tedeschi 1991; IEA 2013). In fact, over the period 2014-2035, approximately $9 \%$ of the cumulative upstream investment is necessary for the development of heavy and extra-heavy oil resources (IEA 2014). For the case of Colombia, heavy and extra-heavy crude oils represent about $45 \%$ of the total local oil production, and it is expected to increase to $60 \%$ by 2018 (Colombia Energía 2013).

The oil and gas industry has avoided the exploitation of heavy oil (HO) and extra-heavy oil (EHO) reservoirs due to the high cost of production, transportation, and refining in comparison with conventional crude oil production. However, in the last decade, the cost of oil and the increasing production of $\mathrm{HO}$ and $\mathrm{EHO}$ have altered opinions about this topic (Castaneda et al. 2014). These types of crude oil have 
disadvantages in their physical properties compared with light crude oil, hindering production from reservoirs. This behavior occurs because $\mathrm{HO}$ and $\mathrm{EHO}$ have extremely high asphaltene contents, which result in high viscosities and low specific gravities (Luo and Gu 2007). The chemical structures of asphaltenes are very complex. They are usually defined as the fraction of oil that is insoluble in low molecular weight $n$-paraffin, such as $n$-heptane or $n$-pentane, while being soluble in light aromatic hydrocarbons, such as toluene, benzene, or pyridine. The structures of asphaltenes are formed by polyaromatic cores attached to aliphatic chains containing heteroatoms, such as nitrogen, oxygen, sulfur, and metals including vanadium, iron, and nickel (Chianelli et al. 2007; Mullins et al. 2012; Mullins 2011; Groenzin and Mullins 1999, 2000). Asphaltenes also contain polar and nonpolar groups and tend to form $i$-mer colloids due to their polarizability and self-associative characteristics (Montoya et al. 2014; Bockrath et al. 1980; Wargadalam et al. 2002; Rosales et al. 2006; Acevedo et al. 1998; Mousavi-Dehghani et al. 2004; Sheu et al. 1994). It has been widely documented that the viscosity of heavy oil can dramatically increase due to asphaltene aggregation (Acevedo et al. 1998; Mousavi-Dehghani et al. 2004; Sheu et al. 1994).

Accordingly, several in situ techniques have been employed for enhancing $\mathrm{HO}$ and $\mathrm{EHO}$ recovery with the objective of upgrading the oil and improving its viscosity and mobility. These techniques include thermal processes, such as in situ combustion and steam-assisted gravity drainage (SAGD) (Cavallaro et al. 2008; Moore et al. 1999; Greaves et al. 2001; Kumar et al. 2011; Kapadia et al. 2010; Speight 1970; Jiang et al. 2005; Fan et al. 2004; Maity et al. 2010), and cold techniques, such as treatments using diluents like natural gas condensate (Luo et al. 2007a, b; James et al. 2008; Castro et al. 2011; Cavallaro et al. 2005). The latter (i.e., cold process) is used to improve the crude oil by dilution or destabilization, and deposition of the asphaltene components in the reservoir by injecting solvents that have a direct impact on viscosity reduction (Luo et al. 2007b; Cavallaro et al. 2005). The more frequently employed thermal techniques for heavy oil upgrading address breaking the heavier compounds of oil using combustion processes (Moore et al. 1999; Cavallaro et al. 2008), low-temperature oxidation ( $\mathrm{Xu}$ et al. 2000; Wichert et al. 1995), aquathermolysis (Jiang et al. 2005; Fan et al. 2004; Maity et al. 2010), and pyrolysis, also called thermal cracking or thermolysis (Speight 1970; Kumar et al. 2011; Monin and Audibert 1988; Nassar et al. 2013a). However, most of these techniques do not exceed $20 \%-25 \%$ oil recovery or $50 \%$ for the steam-assisted gravity drainage (SAGD) process (Butler 1998; Nasr et al. 2003; Hashemi et al. 2013). Nanoparticle technology has emerged as an alternative with a great potential to improve the previously mentioned techniques and increase oil recovery (Hashemi et al. 2014a, b, c; Galarraga and Pereira-Almao 2010; Hashemi et al. 2012; Franco et al. 2013a, b, 2014; Hosseinpour et al. 2014).
Because of their small sizes, high surface area/volume ratios, and tunable chemical characteristics, nanoparticles have exceptional adsorptive and catalytic properties and can be employed for in situ adsorption and post-adsorption catalytic cracking of heavy hydrocarbons, such as asphaltenes (Nassar et al. 2011a, b, c, d, e, 2012a, b, 2013b, 2014; Nassar 2010; Franco et al. 2013c; Hosseinpour et al. 2014; Hashemi et al. 2014c). It has been demonstrated that with advanced research, nanoparticles can be used to sustain the heavy oil industry via the development of environmentally sound processes with cost-effective approaches. For in situ applications, previous studies have provided useful information about the catalytic effects of transition metal oxide and supported nanoparticles on asphaltene gasification (Nassar et al. 2011a, 2015a; Franco et al. 2014), pyrolysis (Nassar et al. 2012b), and oxidation (Franco et al. 2013b, 2015; Nassar et al. 2011b, c, d, e, 2012a, 2013b, 2014).

This work continues previous work (Franco et al. 2013b, 2014, 2015), and it aims at employing $\mathrm{NiO}$ and/or $\mathrm{PdO}$ nanoparticles supported on fumed silica nanoparticles for post-adsorption catalytic thermal cracking of $n-\mathrm{C}_{7}$ asphaltenes. The kinetic study of the thermal cracking of asphaltenes in the presence and absence of nanoparticles was carried out using the isoconversional method. In addition, the mechanism function, kinetic parameters, and transition state thermodynamic functions for the thermal cracking process of $n-C_{7}$ asphaltenes in the presence and absence of nanoparticles are reported for the first time. This work provides potential applications of nanoparticle technology for heavy oil catalytic upgrading and recovery, which could be a viable alternative green technology.

\section{Experimental}

\subsection{Materials}

A sample of "Capella" HO (Putumayo, South of Colombia) was used as the source of $n$ - $\mathrm{C}_{7}$ asphaltenes. This $\mathrm{HO}$ sample has an API of $10.5^{\circ}$ (specific gravity: 0.996; asphaltene content: $9 \mathrm{wt} \%$ ) and viscosity of $4.7 \times 10^{5} \mathrm{cP}$ at $25{ }^{\circ}$ C. $n$-Heptane (99\%, Sigma-Aldrich, St. Louis, MO) was used as a precipitant for isolating solid virgin $n-\mathrm{C}_{7}$ asphaltenes from crude oil by following the standard procedure reported in previous studies (Franco et al. 2013b; Nassar 2010). Toluene (99.5 \%, Merck KGaA, Germany) was used to prepare heavy oil model solutions. Fumed silica (S) nanoparticles were purchased from SigmaAldrich. Distilled water and salt precursors of $\mathrm{Ni}\left(\mathrm{NO}_{3}\right)_{2}\left(6 \mathrm{H}_{2} \mathrm{O}\right)$ (Merck KGaA, Germany) and $\mathrm{Pd}\left(\mathrm{NO}_{3}\right)_{2}$ (Merck KGaA, Germany) were used for nanoparticle functionalization.

The functionalized nanoparticles were prepared following the procedure developed in a previous study 
(Franco et al. 2013b). Briefly, NiO and/or PdO supported on silica nanoparticles were prepared by the incipient wetness method (Ertl et al. 2008), where the support nanoparticles were exposed to the corresponding aqueous solutions of $\mathrm{Ni}\left(\mathrm{NO}_{3}\right)_{2}$ and/or $\mathrm{Pd}\left(\mathrm{NO}_{3}\right)_{2}$ followed by drying at $120{ }^{\circ} \mathrm{C}$ overnight and calcination for $6 \mathrm{~h}$ in air at $450{ }^{\circ} \mathrm{C}$. The amount of $\mathrm{NiO}$ and/or $\mathrm{PdO}$ on the support was controlled to $1 \mathrm{wt} \%-2 \mathrm{wt} \%$ by changing the concentration of aqueous solutions of the corresponding nitrate. The functionalized nanoparticles were labeled by the initial letter of the support ( $\mathrm{S}$ for $7 \mathrm{~nm}$ silica nanoparticles) followed by the symbol of the cation of the resulting metal oxide after the calcination process and the weight percentage of the precursor hydroscopic salt used. The hybrid nanomaterials obtained in this study are called supported hygroscopic salt (SHS). Thus, nanoparticles of SNiXPdY with $1 \mathrm{wt} \% \mathrm{PdO}$ and $1 \mathrm{wt} \% \mathrm{NiO}$ were denoted SNi1Pd1.

Table 1 lists the measured BET surface areas $\left(S_{\mathrm{BET}}\right)$ and mean crystallite sizes of the nanoparticles considered in this study. The $S_{\mathrm{BET}}$ was measured via nitrogen physisorption at $-196{ }^{\circ} \mathrm{C}$ using an Autosorb-1 from Quantachrome after outgassing samples overnight at $140{ }^{\circ} \mathrm{C}$ under high vacuum $\left(10^{-6} \mathrm{mbar}\right)$. The mean crystal size of the nanoparticles was measured by applying the Debye-Scherrer equation to the primary XRD peak. XRD patterns were recorded with an X'Pert PRO MPD X-ray diffractometer from PANalytical using $\mathrm{Cu} K \alpha$ radiation operating at $60 \mathrm{kV}$ and $40 \mathrm{~mA}$ with a $\theta / 2 \theta$ goniometer. Additional information about nanoparticles characterizations can be found in previous studies (Franco et al. 2013b, 2014; Nassar et al. 2015b).

\subsection{Methods}

\subsubsection{Adsorption experiments}

Bath-mode adsorption experiments were carried out at a temperature of $25^{\circ} \mathrm{C}$ using a set of $50-\mathrm{mL}$ glass beakers by adding a fixed amount of nanoparticles to the heavy oil model solutions at a nanoparticle-to-solution ratio of $100 \mathrm{mg}$ to $10 \mathrm{~mL}$ and different initial concentrations $\left(C_{i}\right)$ of $n-\mathrm{C}_{7}$ asphaltenes and mixing for $24 \mathrm{~h}$, as described elsewhere (Franco et al. 2013b, 2014, 2015). Then, the nanoparticles with the adsorbed asphaltenes were separated from the mixture by centrifugation at $4000 \mathrm{rpm}$ for $30 \mathrm{~min}$ to guarantee the maximum recovery of the material (Franco et al. 2015). After that, the nanoparticles containing adsorbed asphaltenes were dried to remove any traces of toluene. At this stage, the nanoparticles containing adsorbed asphaltenes were ready for the thermal analysis experiment. The amount of asphaltenes adsorbed $q$ (mg of $n-\mathrm{C}_{7}$ asphaltenes $/ \mathrm{m}^{2}$ dry surface area of nanoparticles) was obtained by mass balance (Franco et al. 2013b, 2014).

\subsubsection{Thermogravimetric analysis of virgin and adsorbed $n-C_{7}$ asphaltenes}

The dried nanoparticles with adsorbed asphaltenes were subjected to catalytic thermal cracking at temperatures up to $800{ }^{\circ} \mathrm{C}$ in a thermogravimetric analyzer Q50 (TA Instruments, Inc., New Castle, DE) at three different heating rates of 5,10 , and $20{ }^{\circ} \mathrm{C} / \mathrm{min}$ in an Ar atmosphere. The flow of the inert gas was kept constant at $100 \mathrm{~cm}^{3} / \mathrm{min}$ throughout the experiment. The sample mass was kept at approximately $5 \mathrm{mg}$ to avoid diffusion limitations (Nassar et al. 2013a). The selected nanoparticles for TGA experiments had the same loading of asphaltenes per unit surface area of $0.2 \mathrm{mg} / \mathrm{m}^{2}$. The gases produced by the thermal cracking process were analyzed via Fourier Transform Infrared Spectroscopy using an online spectrophotometer IRAffinity-1 (Shimadzu, Japan) coupled to the TGA and operating in transmission mode in the range of $4000-400 \mathrm{~cm}^{-1}$ at a resolution of $2 \mathrm{~cm}^{-1}$ with 16 scans/ min (Franco et al. 2014, 2015; Nassar et al. 2015a). After the thermal cracking process, oxidation under an air flow of $20{ }^{\circ} \mathrm{C} / \mathrm{min}$ from 100 to $800{ }^{\circ} \mathrm{C}$ was conducted to estimate the coke yield (Franco et al. 2014). All experiments were performed in duplicate to confirm reproducibility.

\subsection{Theoretical considerations}

\subsubsection{Estimation of effective activation energy}

The corrected Ozawa-Flynn-Wall equation (OFW) was used to estimate the effective activation energies; assuming that, for a constant reaction conversion, the reaction rate [Eq. (1)] is a function of the state and the temperature (Vyazovkin et al. 2011; Nassar et al. 2014).
Table 1 Estimated particle sizes and surface areas of the selected nanoparticles

\begin{tabular}{llll}
\hline Material & $S_{\text {BET }}\left( \pm 0.01, \mathrm{~m}^{2} / \mathrm{g}\right)$ & $\mathrm{dp}-\mathrm{NiO}( \pm 0.2, \mathrm{~nm})$ & $\mathrm{dp}-\mathrm{PdO}( \pm 0.2, \mathrm{~nm})$ \\
\hline $\mathrm{S}$ & 389 & - & - \\
$\mathrm{SNi} 2$ & 234 & 2.9 & - \\
$\mathrm{SPd} 2$ & 205 & - & 4.1 \\
SNi1Pd1 & 202 & 1.3 & 2.2 \\
\hline
\end{tabular}


$\frac{\mathrm{d} \alpha}{\mathrm{d} t}=A_{\alpha} \exp \left(-\frac{E_{\alpha}}{R T}\right) f(\alpha)$

where $A_{\alpha}$ is the pre-exponential factor, $\mathrm{s}^{-1} ; E_{\alpha}$ is the effective activation energy for a constant conversion, $\mathrm{kJ} / \mathrm{mol} ; R$ is the ideal gas constant, $\mathrm{J} /(\mathrm{mol} \mathrm{K}) ; T$ is the reaction temperature, $\mathrm{K}$, and $\alpha$ is the reaction conversion as described by Eq. (2):

$\alpha=\frac{m_{0}-m_{t}}{m_{0}-m_{f}}$

where $m_{0}$ is the initial mass of the sample, $m_{f}$ the final mass of the sample, and $m_{t}$ is the mass at a given temperature. Defining the heating rate as $\beta=\mathrm{d} T / \mathrm{d} t$ and after integrating, Eq. (3) is obtained:

$g(\alpha)=\int_{0}^{\alpha} \frac{\mathrm{d} \alpha}{f(\alpha)}=\int_{0}^{T} \frac{A_{\alpha} \exp \left(-E_{\alpha} / R T\right)}{\beta} \mathrm{d} T$.

The right-hand side of Eq. (3) is solved via a commonly employed approach for isoconversional methods by defining $x=-E_{\alpha} / R T$ and applying the Doyle approximation (Doyle 1961, 1965). After rearrangement, the effective activation energy at each value of $\alpha$ can be estimated from the slope of the linear fit from the plot of $\ln (\beta)$ against $1 / T$ according to Eq. (4) (Ozawa 1965; Flynn and Wall 1966; Nassar et al. 2014):

$\ln (\beta)=\ln \left(\frac{A_{\alpha} E_{\alpha}}{205.54 R \cdot g(\alpha)}\right)-1.052 \frac{E_{\alpha}}{R T}$.

The error in the estimation of $E_{\alpha}$ due to Doyle's approximation is corrected using a correction factor as shown in Eq. (5) (Nassar et al. 2014; Opfermann and Kaisersberger 1992; Flynn 1983):

$E_{\alpha, \text { corrected }}=E_{\alpha} / F\left(x_{m}\right)$

with

$x_{m}=E_{\alpha} / R T_{m}$

and

$F\left(x_{m}\right)=0.94961\left(1+\frac{7.770439+x_{m}}{1+4.56092 x_{m}+0.48843 x_{m}^{2}}\right)$,

where $T_{m}$ is the mean temperature at the determined value for the selected $\alpha, \mathrm{K}$.

\subsubsection{Estimation of the thermodynamic parameters of the transition state functions}

The thermodynamic parameters of the transition state functions, such as changes in the Gibbs free energy $\left(\Delta G^{\ddagger}\right)$, enthalpy $\left(\Delta H^{\ddagger}\right)$, and entropy $\left(\Delta S^{\ddagger}\right)$ of activation, are of importance for understanding the catalytic role of the SHS nanoparticles. A conversion of $50 \%$ at a fixed heating rate of $5{ }^{\circ} \mathrm{C} / \mathrm{min}$ was used for the estimation of the thermodynamic parameters at the respective temperature, $T_{p}(\mathrm{~K})$. Hence, $\Delta G^{\ddagger}$ can be estimated as follows:

$\Delta G^{\ddagger}=\Delta H^{\ddagger}-T_{p} \Delta S^{\ddagger}$,

where $\Delta H^{\ddagger}$ can be approximated to $\Delta H^{\ddagger}=E^{\ddagger}-R T_{p}$, with $E^{\ddagger}$ as the effective activation energy at the selected $T_{p}$ (Nassar et al. 2014). In addition, after rearrangement of the Arrhenius and Eyring equations (Nassar et al. 2014; Rooney 1995; Young 1966; Sestak 1984), $\Delta S^{\ddagger}$ can be estimated as follows:

$\Delta S^{\ddagger}=R \ln \left(\frac{A h}{e T_{p} k_{B}}\right)$,

where $h\left(6.6261 \times 10^{-34} \mathrm{~J} \mathrm{~s}\right)$ is the Planck's constant, $e$ (2.7183) is the Neper number, and $k_{B}\left(1.3806 \times 10^{-23} \mathrm{~J} / \mathrm{K}\right)$ is Boltzmann's constant. The pre-exponential factor $A$ can be estimated from the intercept of the linear plots of $\ln [g(\alpha)]$ against $\ln (\beta)$ according to Eq. (4) (Nassar et al. 2014). The $n$ order kinetic expressions $(1-\alpha)^{-n+1}-1$ and $\frac{1}{n-1}(1-\alpha)^{n}$ were used for the estimation of the best-fit chemical reaction models $g(\alpha)$ and $f(\alpha)$, respectively. $n$ is the mechanism order and was estimated as the value where the slope and the $R^{2}$ of the linear plots of $\ln [g(\alpha)]$ against $\ln (\beta)$ are equal to -1.0 and 1.0, respectively (Nassar et al. 2014).

\section{Results and discussion}

\subsection{Asphaltene adsorption onto fumed silica and SHS}

$n-\mathrm{C}_{7}$ asphaltene adsorption on the surface area-normalized basis was higher for the SHS nanoparticles than for the fumed silica support, and it followed the order SNi1Pd1 $>$ SNi2 $>$ SPd2 $>$ S (Franco et al. 2014). This result was attributed to the synergistic effects of $\mathrm{NiO}$ and PdO, which have different selectivities toward the asphaltene compounds. As the purpose of this study is to investigate the role of nanoparticles in the catalytic thermal cracking of adsorbed asphaltenes, we will limit our discussion on the role of the nanoparticles as nanocatalysts. Detailed discussion of the roles of the nanoparticles as adsorbents for $n-\mathrm{C}_{7}$ asphaltenes and full descriptions of the adsorption isotherms can be found in a previous study (Franco et al. 2014). 


\subsection{Catalytic thermal cracking of $n-C_{7}$ asphaltenes}

\subsubsection{Rate of mass loss of $n-C_{7}$ asphaltenes in the presence and absence of silica nanoparticles}

Figure 1 shows the rate of mass loss of virgin $n$ - $\mathrm{C}_{7}$ asphaltenes and $n-\mathrm{C}_{7}$ asphaltenes in the presence of silica nanoparticles in the thermal cracking reaction. As shown, virgin asphaltene decomposition started at approximately $310{ }^{\circ} \mathrm{C}$ and finished at approximately $660{ }^{\circ} \mathrm{C}$ with a maximum mass loss rate at approximately $448{ }^{\circ} \mathrm{C}$. These findings are in very close agreement with those reported by Nassar et al. (2012b) for the pyrolysis of asphaltenes extracted from a vacuum residue from Athabasca EHO; they found that thermal decomposition occurred between 300 and $700{ }^{\circ} \mathrm{C}$. The $n-\mathrm{C}_{7}$ asphaltenes thermal decomposition could be fractionated into three steps: (1) the breaking of intermolecular associations, loss of short alkyl chains, and weak chemical bonds such as sulfur bridges (Trejo et al. 2010) at temperatures lower than $350{ }^{\circ} \mathrm{C}$; (2) the rupture of longer alkyl groups and the opening of the PAHs between 350 and $500{ }^{\circ} \mathrm{C}$; and (3) coke formation at temperatures above $500{ }^{\circ} \mathrm{C}$ (Nassar et al. 2012b). The catalytic effect of the silica nanoparticles is also found in Fig. 1. The catalytic thermal decomposition of $n$ - $\mathrm{C}_{7}$ asphaltenes in the presence of silica nanoparticles can be divided into two main regions: one from 300 to $500{ }^{\circ} \mathrm{C}$ and a second one from 500 to $800{ }^{\circ} \mathrm{C}$. The first region corresponds to the breaking of the alkyl side chains and the PAHs. In this region, the maximum peak of the rate of mass loss was shifted to the left by approximately $40{ }^{\circ} \mathrm{C}$, in comparison with that of virgin $n-\mathrm{C}_{7}$ asphaltenes, indicating that the reactions involved in this stage took place earlier than those for the virgin $n-\mathrm{C}_{7}$ asphaltenes. However, according to the rate of mass loss above $500{ }^{\circ} \mathrm{C}$, it seems that some addition reactions occurred in the first stage and

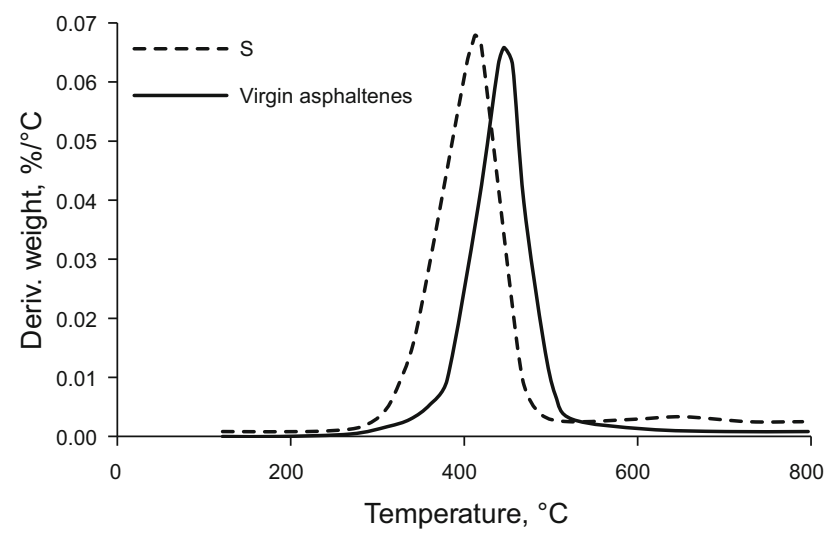

Fig. 1 Rate of mass loss of $n-C_{7}$ asphaltene in thermal cracking reaction in the presence and absence of fumed silica nanoparticles. Amount adsorbed $=0.2 \mathrm{mg} / \mathrm{m}^{2} ;$ argon flow $=100 \mathrm{~cm}^{3} / \mathrm{min}$, heating rate $=10^{\circ} \mathrm{C} / \mathrm{min}$ the decomposition of the resultant compounds took place at up to $800{ }^{\circ} \mathrm{C}$, indicating that silica nanoparticles could lead to less coke formation in comparison to virgin $n$ - $\mathrm{C}_{7}$ asphaltenes.

For the functionalized nanoparticles, Fig. 2 shows the plot of the rate of mass loss of monometallic $\mathrm{SNi} 2$ and SPd2. As shown, two peaks were found below $660^{\circ} \mathrm{C}$ for both SNi2 and SPd2. For SNi2 nanoparticles, the first peak appeared near to $300{ }^{\circ} \mathrm{C}$, and the second one (main peak) was shifted to the left by approximately $30^{\circ} \mathrm{C}$ in comparison with the main peak of the virgin $n$ - $\mathrm{C}_{7}$ asphaltenes. These results indicated that $\mathrm{SNi} 2$ nanoparticles had a higher catalytic effect on the $n-\mathrm{C}_{7}$ asphaltene thermal cracking than the silica support. For SPd2 nanoparticles, the first peak appeared near $210^{\circ} \mathrm{C}$, and the second one was in the same position as that for the SNi2 nanoparticles. It is worth mentioning here that the magnitude of the first peak was about one-third higher than that of the second peak, indicating that more components were decomposed in this region (the first peak). This result is in agreement with a previous work on the oxidation of $n-\mathrm{C}_{7}$ asphaltenes that showed asphaltene decomposition in the presence of SPd2 took place at temperatures near to $220{ }^{\circ} \mathrm{C}$ (Franco et al. 2013b). For both monometallic SHS, at temperatures higher than $660{ }^{\circ} \mathrm{C}$, it can be found that some addition reactions could occur. However, with SPd2 nanoparticles, only a small peak appeared at $720{ }^{\circ} \mathrm{C}$, and then, the rate of mass loss drop off to zero, indicating that monometallic SHS functionalized with $\mathrm{PdO}$ can lead to the suppression of coke formation.

Figure 3 shows the plot of the rate of mass loss for $n-C_{7}$ asphaltenes in the presence of SNi1Pd1 nanoparticles. The synergistic effect of the $\mathrm{NiO}$ and the $\mathrm{PdO}$ was clearly found. Two mean peaks appeared at 220 and $300{ }^{\circ} \mathrm{C}$, showing that the selectivity of $\mathrm{NiO}$ and $\mathrm{PdO}$ for certain components can greatly enhance the catalytic activity. In



Fig. 2 Rate of mass loss of $n-\mathrm{C}_{7}$ asphaltene via thermal cracking in the presence and absence of monometallic SHS ( $\mathrm{SNi} 2$ and SPd2). Amount adsorbed $=0.2 \mathrm{mg} / \mathrm{m}^{2} ;$ argon flow $=100 \mathrm{~cm}^{3} / \mathrm{min}$, heating rate $=10^{\circ} \mathrm{C} / \mathrm{min}$ 


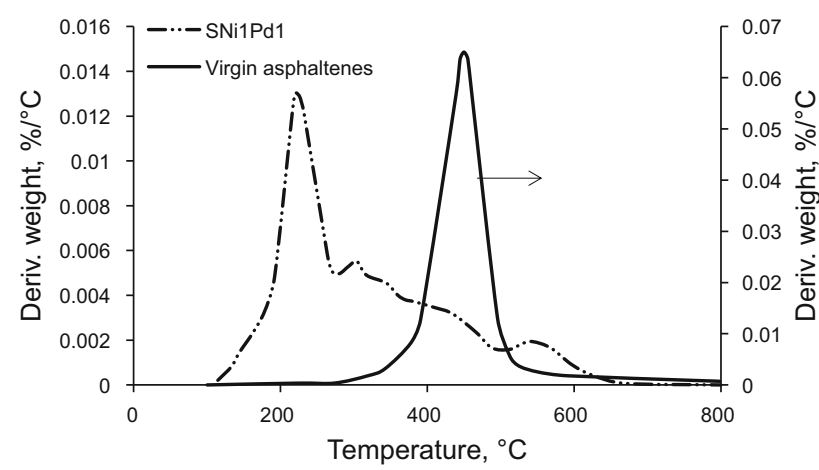

Fig. 3 Rate of mass loss of $n-C_{7}$ asphaltene via thermal cracking in the presence and absence of bimetallic SHS. Amount adsorbed $=0.2 \mathrm{mg} /$ $\mathrm{m}^{2}$; argon flow $=100 \mathrm{~cm}^{3} / \mathrm{min}$, heating rate $=10^{\circ} \mathrm{C} / \mathrm{min}$

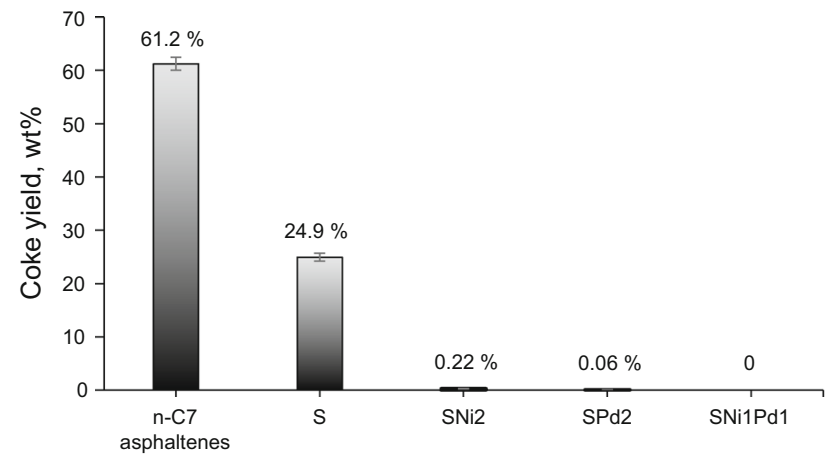

Fig. 4 Coke yield after the thermal cracking process of $n-\mathrm{C}_{7}$ asphaltenes in the presence and absence of the evaluated nanoparticles

addition, a third small peak appeared at $530{ }^{\circ} \mathrm{C}$ that was associated with the decomposition of the new compounds from the addition reactions. For temperatures above $660{ }^{\circ} \mathrm{C}$, no mass loss was observed, indicating that bimetallic nanoparticles were useful for the suppression of coke formation with a better efficiency than SPd2 nanoparticles.

\subsubsection{Presence and absence of nanoparticles}

The $n-\mathrm{C}_{7}$ asphaltene thermal cracking could lead to different solid and gaseous sub-products to different extents depending on the system evaluated. As the temperature increases, radical species may be stabilized to form new lighter compounds, such as hydrocarbons with lower molecular weights, $\mathrm{CO}$ and $\mathrm{CO}_{2}$, among others (Savage et al. 1985; Ali and Saleem 1991; Hosseinpour et al. 2014). However, the recombination of free radial species leads to addition reactions that result in changes to the chemical structures of the $n-\mathrm{C}_{7}$ asphaltenes and, therefore, result in heavier and more refractory compounds than the initial $n$ $\mathrm{C}_{7}$ asphaltenes (Alshareef et al. 2011; Habib et al. 2013; Sanford 1994).
The coke yield after the thermal cracking process was evaluated for the virgin $n-\mathrm{C}_{7}$ asphaltenes and the $n-\mathrm{C}_{7}$ asphaltenes in the presence of the evaluated nanoparticles. Reactions, such as addition of olefin free radicals (Gray and McCaffrey 2002), cross-linking between aromatic clusters (Habib et al. 2013), and bridging of aromatics by alkyl chains (Alshareef et al. 2011), were likely to be responsible for the formation of more refractory compounds. Figure 4 shows the results obtained for coke yield of the five evaluated samples. As shown, the presence of nanoparticles significantly reduced the coke formation compared with the virgin $n-\mathrm{C}_{7}$ asphaltenes. In the presence of $\mathrm{S}$ nanoparticles, the coke yield was reduced by approximately $47 \%$ compared with the virgin asphaltenes. However, with the functionalized nanoparticles, the inhibition of coke formation was greatly enhanced, with reductions greater than $99 \%$ for all the SHS. It is worth mentioning here that synergistic effects were also found for the bimetallic SHS SNi1Pd1, resulting in $100 \%$ inhibition of coke formation with this material, presumably due to the inhibition of $n-\mathrm{C}_{7}$ asphaltene self-association on the nanoparticle surfaces (Franco et al. 2015).

The thermal cracking reactions of virgin $n-\mathrm{C}_{7}$ asphaltenes and $n-\mathrm{C}_{7}$ asphaltenes in the presence of SNi1Pd1 nanoparticles were selected for gaseous product analysis. Figure 5 shows the evolution of $\mathrm{CO}_{2}$, light hydrocarbons ( $\mathrm{LHC}$ ), and $\mathrm{CH}_{4}$ during the thermal cracking of $n-\mathrm{C}_{7}$ asphaltenes in (a) the absence of and (b) the presence of SNi1Pd1 nanoparticles at a fixed heating rate of $10{ }^{\circ} \mathrm{C} / \mathrm{min}$. As shown, the gas profile followed, to some degree, the shapes of the mass loss rate curves for the virgin $n-\mathrm{C}_{7}$ asphaltenes and the $n-\mathrm{C}_{7}$ asphaltenes with SNi1Pd1 nanoparticles, confirming the catalytic activity of the bimetallic SHS toward $n-\mathrm{C}_{7}$ asphaltene thermal decomposition. Figure 5 also showed that, in both cases, the amount of $\mathrm{CO}_{2}$ produced was higher than the production of $\mathrm{LHC}$ and $\mathrm{CH}_{4}$. The results are in agreement with that by Hosseinpour et al. (2014), who evaluated the pyrolysis of $n-\mathrm{C}_{7}$ asphaltenes in the presence of $\mathrm{NiO}$ and found that the $\mathrm{CO}_{2}$ production was higher than that of hydrocarbons. The production of $\mathrm{CO}_{2}$ could be attributed to two main oxygen sources: i) lattice oxygen from the SHS and ii) the oxygen content of the asphaltenes (Hosseinpour et al. 2014). Free carbon radicals could react with the oxygen released from $\mathrm{O}$-containing functional groups in the $n-\mathrm{C}_{7}$ asphaltene structures to form $\mathrm{CO}$; the $\mathrm{CO}$ was chemisorbed on the catalyst surface, and after reaction with the surface oxygen, it is desorbed as $\mathrm{CO}_{2}$. The oxygen content in the $n-\mathrm{C}_{7}$ asphaltene structures and the mobility of the lattice oxygen in the adsorbent structures play important roles in the stabilization of free radicals, the formation of carbon oxides and, subsequently, the suppression of coke formation. Thus, because the coke yield 

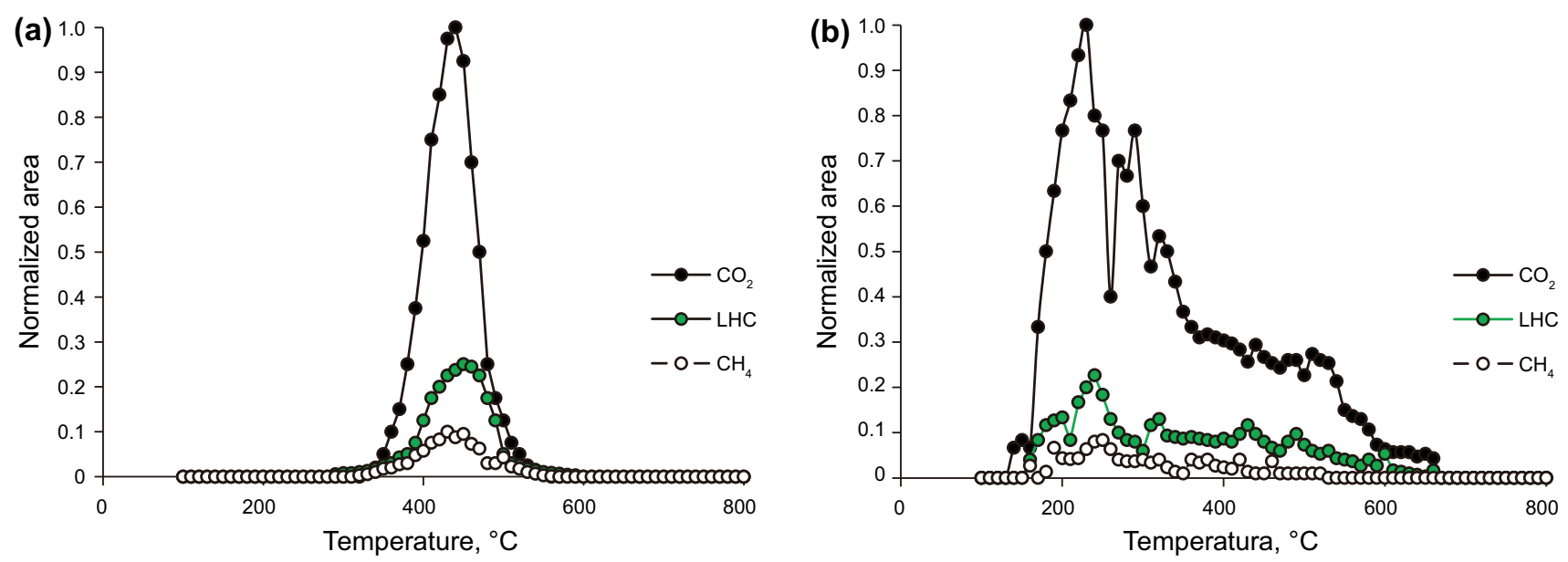

Fig. 5 Profiles of $\mathrm{CO}_{2}, \mathrm{LHC}$, and $\mathrm{CH}_{4}$ evolution during thermal cracking of virgin $n$ - $\mathrm{C}_{7}$ asphaltenes (a) and $n$ - $\mathrm{C}_{7}$ asphaltenes in the presence of SNi1Pd1 nanoparticles (b). Amount adsorbed $=0.2 \mathrm{mg} / \mathrm{m}^{2}$; argon flow rate $=100 \mathrm{~cm}^{3} / \mathrm{min}$; heating rate $=10^{\circ} \mathrm{C} / \mathrm{min}$

was minimized with SHS, one can infer that the lattice oxygen in the functionalized nanoparticles is more mobile and more prone to react than the oxygen in the support.

\subsection{Estimation of the effective activation energies}

The effective activation energies $\left(E_{\alpha}\right)$ were estimated by the isoconversional OFW method. Panels a-e in Fig. 6 show the percentage of conversion as a function of temperature for (a) virgin $n-C_{7}$ asphaltenes and asphaltenes in the presence of (b) fumed silica, (c) SNi2, (d) SPd2, and (e) SNi1Pd1 nanoparticles at different heating rates of 5, 10 , and $20^{\circ} \mathrm{C} / \mathrm{min}$. As shown, for all the materials, the gap between the three curves at different heating rates was almost constant, and there was no overlapping, which allows for the successful use of the OFW method avoiding the risk of the calculation with underestimated values. Taking a fixed heating rate of $10{ }^{\circ} \mathrm{C} / \mathrm{min}$ for comparison, the catalytic effect of the nanoparticles could be found via the higher conversion at lower temperatures. For a fixed conversion of $40 \%$, the catalytic activity follows the order of SNi1Pd1 $>$ SPd2 $>$ SNi2 $>$ S, and for all the nanoparticles, the temperature of $n-\mathrm{C}_{7}$ asphaltene decomposition was lower than that of the virgin $n-\mathrm{C}_{7}$ asphaltene decomposition.

Figure 7 shows $E_{\alpha}$ for the thermal cracking of $n-\mathrm{C}_{7}$ asphaltenes with different nanoparticles and of the virgin $n$ $\mathrm{C}_{7}$ asphaltenes as a function of the degree of conversion estimated by Eq. (5). It was found that $E_{\alpha}$ was not the same for all the conversion degrees, indicating that the $n-\mathrm{C}_{7}$ asphaltene thermal cracking was not a single-mechanism process (Nassar et al. 2014), due to different reaction paths might occur, such as aromatization, dealkylation, fragmentation, isomerization, and/or rupture of naphthene rings (Siddiqui 2010). For the virgin $n-\mathrm{C}_{7}$ asphaltenes, the activation energy varied between 117 and $195 \mathrm{~kJ} / \mathrm{mol}$, while for SNi1Pd1, $E_{\alpha}$ ranged between 55 and $170 \mathrm{~kJ} / \mathrm{mol}$. When the conversion percentage was less than $50 \%$, the general trend for the effective activation energy was $\mathrm{SNi} 1 \mathrm{Pd} 1 \approx \mathrm{SPd} 2<\mathrm{SNi} 2<\mathrm{S}<$ virgin $n-\mathrm{C}_{7}$ asphaltenes. However, when the conversion percentage was above $60 \%$, the trend for $E_{\alpha>60 \%}$ was virgin asphaltenes $<$ SNi1Pd $1 \approx \mathrm{SPd} 2<\mathrm{SNi} 2 \approx \mathrm{S}$. This results might be attributed to the addition reactions mentioned above that lead to decomposition of the new compounds at temperatures higher than that for virgin $n-\mathrm{C}_{7}$ asphaltenes decomposition. It is worth mentioning that, for the thermal cracking of $n-\mathrm{C}_{7}$ asphaltenes with nanoparticles functionalized with $\mathrm{PdO}$, the values of $E_{\alpha}$ never reached the highest value of $E_{\alpha}$ for virgin $n$ - $\mathrm{C}_{7}$ asphaltenes, confirming that, with these nanoparticles, the addition reactions were suppressed, and there was little formation of components with larger molecular weights than the virgin $n-C_{7}$ asphaltenes.

\subsection{Thermodynamic parameters of the transition state functions}

The kinetic parameters and thermodynamic properties of the transition state functions for the thermal cracking of $n-\mathrm{C}_{7}$ asphaltenes in the presence and absence of the nanoparticles were studied following the procedure described in Sect. 2.3 and are presented in Table 2. As shown, the values of mechanism order $n$ ranged from 1.5 to 10 with the slope values between -1.07 and -0.97 for $R^{2}=0.99$. However, it is worth mentioning that the values of $n>4$ lack chemical significance and were only used as fitting parameters for the description of the kinetic equation and the estimation of the thermodynamic properties. This is because the chemical compositions and structures are very complex and can result in a series of unidentified simultaneous reactions. 

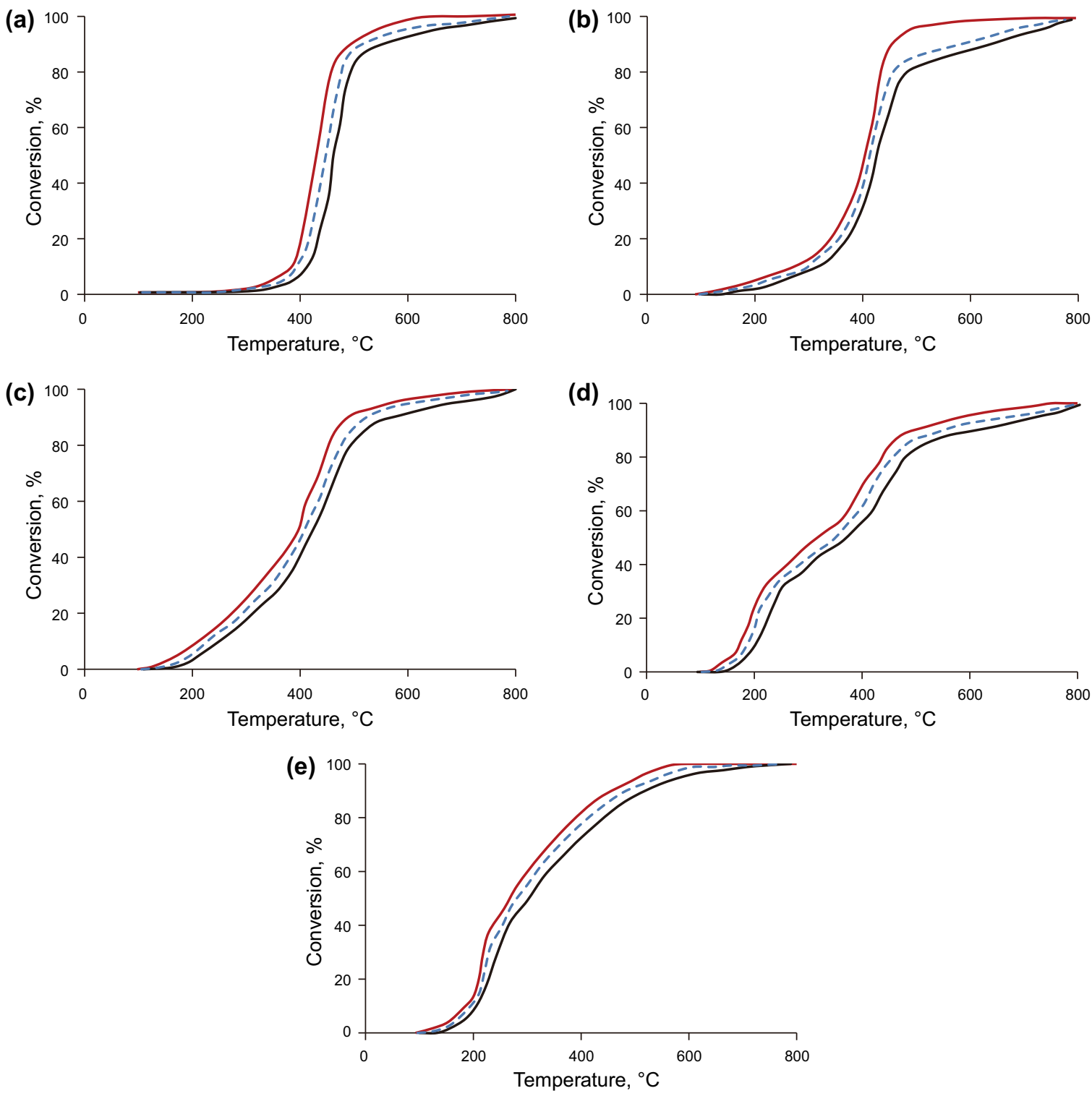

Fig. 6 Percent conversion for pyrolysis of virgin $n$ - $\mathrm{C}_{7}$ asphaltenes (a) and $n$ - $\mathrm{C}_{7}$ asphaltenes in the presence of $\mathrm{S}(\mathbf{b}), \mathrm{SNi} 2(\mathbf{c}), \mathrm{SPd} 2(\mathbf{d})$, and SNi1Pd1 (e) nanoparticles at different heating rates of 5 (red dashed line), 10 (blue dashed line), and $20^{\circ} \mathrm{C} / \mathrm{min}$ (thick black line)

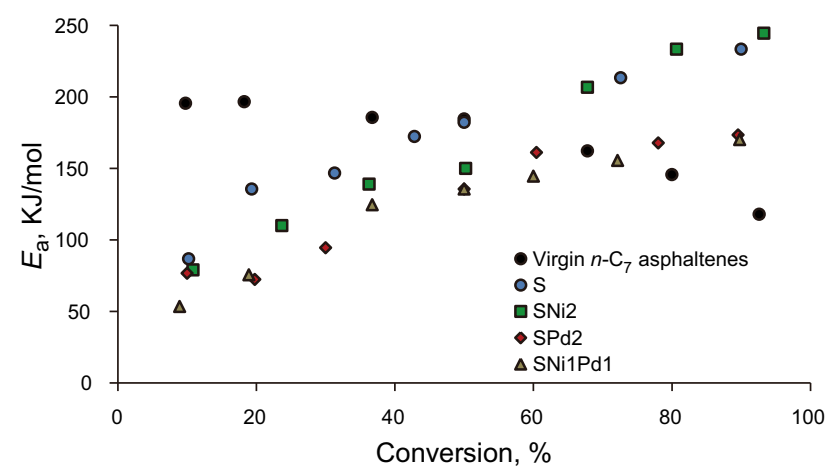

Fig. 7 Effective activation energies estimated by the OFW method as a function of the conversion for fumed silica and SHS nanoparticles
Additionally, different values of $n$ imply that the thermal cracking of $n-\mathrm{C}_{7}$ asphaltenes in the presence or absence of the nanoparticles is not a single-mechanism process, highly dependent on the chemical nature of the nanoparticles. Table 2 shows that the trend of the change in the enthalpy $\left(\Delta H^{\ddagger}\right.$ ) of activation follows the order of virgin $n-\mathrm{C}_{7}$ asphaltenes $>\mathrm{S}>\mathrm{SNi} 2>\mathrm{SPd} 2>\mathrm{SNi} 1 \mathrm{Pd} 1, \quad$ indicating that the highest catalytic effect was obtained with the bimetallic SHS as its reduction in $\Delta H^{\ddagger}$ was highest among the evaluated systems; the same trend can be found for Gibbs free energy $\left(\Delta G^{\dagger}\right)$. In addition, according to the negative values of the entropy $\Delta S^{\dagger}$, it can be inferred that the entropy 
Table 2 Kinetic parameters and thermodynamic properties of the transition state functions for the thermal cracking of $n$ - $\mathrm{C}_{7}$ asphaltenes in the presence and absence of SHS for a fixed value of $\alpha=50 \%$

\begin{tabular}{lcccccccc}
\hline Material & $n$ & Slope & $R^{2}$ & $A, \times 10^{-5} \mathrm{~s}^{-1}$ & Kinetic equation & $\Delta S^{\ddagger}, \mathrm{J} /(\mathrm{mol} \mathrm{K})$ & $\Delta H^{\ddagger}, \mathrm{kJ} / \mathrm{mol}$ & $\Delta G^{\ddagger}, \mathrm{kJ} / \mathrm{mol}$ \\
\hline Virgin $n$-C 7 asphaltenes & 1.5 & -1.00 & 0.99 & 1.76 & $\frac{\mathrm{d} \alpha}{\mathrm{d} t}=2 A_{\alpha} \exp \left(-\frac{E_{\alpha}}{R T}\right)(1-\alpha)^{3 / 2}$ & -160.22 & 179.99 & 115.86 \\
S & 5 & -1.07 & 0.99 & 28.05 & $\frac{\mathrm{d} \alpha}{\mathrm{d} t}=\frac{A_{\alpha}}{5} \exp \left(-\frac{E_{\alpha}}{R T}\right)(1-\alpha)^{6}$ & -137.00 & 176.09 & 97.45 \\
SNi2 & 7 & -1.01 & 0.99 & 39.84 & $\frac{\mathrm{d} \alpha}{\mathrm{d} t}=\frac{A_{\alpha}}{7} \exp \left(-\frac{E_{\alpha}}{R T}\right)(1-\alpha)^{8}$ & -133.65 & 143.39 & 90.22 \\
SPd2 & 9 & -1.02 & 0.99 & 26.47 & $\frac{\mathrm{d} \alpha}{\mathrm{d} t}=\frac{A_{\alpha}}{9} \exp \left(-\frac{E_{\alpha}}{R T}\right)(1-\alpha)^{10}$ & -136.05 & 129.03 & 81.49 \\
SNi1Pd1 & 10 & -0.97 & 0.99 & 5.91 & $\frac{\mathrm{d} \alpha}{\mathrm{d} t}=\frac{A_{\alpha}}{10} \exp \left(-\frac{E_{\alpha}}{R T}\right)(1-\alpha)^{11}$ & -147.91 & 130.59 & 78.31 \\
\hline
\end{tabular}

of the activated state is lower than that of the initial state (Nassar et al. 2014).

\section{Conclusions}

This study provides important insights into the effects of $\mathrm{NiO}$ and $\mathrm{PdO}$ supported on fumed silica nanoparticles on the thermal cracking of $n-\mathrm{C}_{7}$ asphaltenes. The catalytic thermal cracking process was performed using a TGA/FTIR system. The reaction kinetics were studied using the isoconversional Ozawa-Flynn-Wall (OFW) corrected method. The mechanism function, kinetic parameters, and transition state thermodynamic functions for the thermal cracking of $n$ - $\mathrm{C}_{7}$ asphaltenes were nanoparticle dependent. PdO supported on silica nanoparticles showed better catalytic activity than $\mathrm{NiO}$ supported on silica nanoparticles. Nevertheless, bimetallic nanoparticles ( $\mathrm{NiO}$ and $\mathrm{PdO}$ ) supported on silica nanoparticles showed the highest catalytic activity. The excellent behavior of the bimetallic nanoparticles could be attributed the synergistic effects of $\mathrm{NiO}$ and $\mathrm{PdO}$ on the silica surface, which leads to higher selectivity than the independent effects of the monometallic ones. The computational kinetics study of $n-\mathrm{C}_{7}$ asphaltenes thermal cracking in the presence and absence of nanoparticles were carried out using the isoconversional method. The reaction kinetic parameters, namely, activation energy $\left(E_{\alpha}\right)$, the pre-exponential factor $\left(A_{\alpha}\right)$ and the most probable mechanism functions $f(\alpha)$ were determined. Thermodynamic transition state parameters, namely, changes in Gibbs free energy of activation $\left(\Delta G^{\ddagger}\right)$, enthalpy of activation $\left(\Delta H^{\ddagger}\right)$, and entropy of activation $\left(\Delta S^{\ddagger}\right)$ were also calculated through kinetic parameters. Bimetallic $(\mathrm{NiO}$ and $\mathrm{PdO}$ ) supported on silica nanoparticles showed the highest catalytic activity toward $n-\mathrm{C}_{7}$ asphaltenes thermal cracking, confirmed by the lowest effective activation energy trend and lowest values of reaction temperature, $\Delta H^{\ddagger}$, and $\Delta G^{\ddagger}$. This work provides new insights into the use of nanoparticles for enhancing the in situ heavy and extraheavy oil upgrading and recovery processes.
Acknowledgments The authors acknowledge COLCIENCIAS, ECOPETROL S.A., and Universidad Nacional de Colombia for the support provided in Agreement No. 264 of 2013 and the Cooperation Agreement 04 of 2013, respectively. The authors are also grateful to the Natural Sciences and Engineering Research Council of Canada (NSERC) and the Department of Chemical and Petroleum Engineering at the Schulich School of Engineering at the University of Calgary.

Open Access This article is distributed under the terms of the Creative Commons Attribution 4.0 International License (http://crea tivecommons.org/licenses/by/4.0/), which permits unrestricted use, distribution, and reproduction in any medium, provided you give appropriate credit to the original author(s) and the source, provide a link to the Creative Commons license, and indicate if changes were made.

\section{References}

Acevedo S, Castillo J, Fernández A, et al. A study of multilayer adsorption of asphaltenes on glass surfaces by photothermal surface deformation. Relation of this adsorption to aggregate formation in solution. Energy Fuels. 1998;12(2):386-90.

Ali MF, Saleem M. Thermal decomposition of Saudi crude oil asphaltenes. Fuel Sci Technol Int. 1991;9(4):461-84.

Alshareef AH, Scherer A, Tan X, et al. Formation of archipelago structures during thermal cracking implicates a chemical mechanism for the formation of petroleum asphaltenes. Energy Fuels. 2011;25(5):2130-6.

Bockrath BC, LaCount RB, Noceti RP. Coal-derived asphaltenes: effect of phenol content and molecular weight on viscosity of solutions. Fuel. 1980;59(9):621-6.

Butler R. SAGD comes of age! J Can Pet Technol. 1998;37(07):9-12.

Castaneda LC, Munoz JA, Ancheyta J. Current situation of emerging technologies for upgrading of heavy oils. Catal Today. 2014;220:248-73.

Castro LV, Flores EA, Vazquez F. Terpolymers as flow improvers for Mexican crude oilst. Energy Fuels. 2011;25(2):539-44.

Cavallaro A, Galliano G, Sim S, et al. Laboratory investigation of an innovative solvent based enhanced recovery and in situ upgrading technique. In: Canadian international petroleum conference. Petroleum Society of Canada; 2005.

Cavallaro A, Galliano G, Moore R, et al. In situ upgrading of Llancanelo heavy oil using in situ combustion and a downhole catalyst bed. J Can Pet Technol. 2008;47(9):23-31.

Chianelli RR, Siadati M, Mehta A, et al. Self-assembly of asphaltene aggregates: synchrotron, simulation and chemical modeling techniques applied to problems in the structure and reactivity of asphaltenes. In: Mullins OC, Sheu EC, Hammami A, Marshall 
AG, editors. Asphaltenes, heavy oils, and petroleomics. New York: Springer; 2007.

Colombia Energía. Crudos pesados, la gran apuesta del sector. http:// www.colombiaenergia.com/featured-article/crudos-pesados-la-gr an-apuesta-del-sector (2013). Accessed 10 Aug 2015.

Doyle C. Synthesis and evaluation of thermally stable polymers. II. Polymer evaluation. Appl Polym Sci. 1961;5:285-92.

Doyle CD. Series approximations to the equation of thermogravimetric data. Nature. 1965;207:290-1.

Ertl G, Knözinger H, Weitkamp J. Preparation of Solid Catalysts. New York: Wiley; 2008.

Fan H, Zhang Y, Lin Y. The catalytic effects of minerals on aquathermolysis of heavy oils. Fuel. 2004;83(14):2035-9.

Flynn J. The isoconversional method for determination of energy of activation at constant heating rates: corrections for the Doyle approximation. J Therm Anal Calorim. 1983;27(1):95-102.

Flynn JH, Wall LA. A quick, direct method for the determination of activation energy from thermogravimetric data. J Polym Sci C Polym Lett. 1966;4(5):323-8.

Franco C, Patiño E, Benjumea P, et al. Kinetic and thermodynamic equilibrium of asphaltenes sorption onto nanoparticles of nickel oxide supported on nanoparticulated alumina. Fuel. 2013a;105:408-14.

Franco CA, Montoya T, Nassar NN, et al. Adsorption and subsequent oxidation of Colombian asphaltenes onto nickel and/or palladium oxide supported on fumed silica nanoparticles. Energy Fuels. 2013b;27(12):7336-47.

Franco CA, Nassar NN, Ruiz MA, et al. Nanoparticles for inhibition of asphaltenes damage: adsorption study and displacement test on porous media. Energy Fuels. 2013c;27(6):2899-907. doi:10. 1021/ef4000825.

Franco CA, Nassar NN, Montoya T, Cortés FB. NiO and PdO supported on fumed silica nanoparticles for adsorption and catalytic steam gasification of Colombian $\mathrm{C} 7$ asphaltenes. In: Ambrosio J, editor. Handbook on Oil Production Research. New York: Nova Science Publishers; 2014

Franco CA, Nassar NN, Montoya T, et al. Influence of asphaltene aggregation on the adsorption and catalytic behavior of nanoparticles. Energy Fuels. 2015;29(3):1610-21.

Galarraga CE, Pereira-Almao P. Hydrocracking of Athabasca bitumen using submicronic multimetallic catalysts at near inreservoir conditions. Energy Fuels. 2010;24(4):2383-9.

Ghannam MT, Hasan SW, Abu-Jdayil B, et al. Rheological properties of heavy \& light crude oil mixtures for improving flowability. J Pet Sci Eng. 2012;81:122-8.

Gray MR, McCaffrey WC. Role of chain reactions and olefin formation in cracking, hydroconversion, and coking of petroleum and bitumen fractions. Energy Fuels. 2002;16(3):756-66.

Greaves M, Saghr A, Xia T, et al. THAI-new air injection technology for heavy oil recovery and in situ upgrading. J Can Pet Technol. 2001;40(3):38-47.

Groenzin H, Mullins OC. Asphaltene molecular size and structure. J Phys Chem A. 1999;103(50):11237-45.

Groenzin H, Mullins OC. Molecular size and structure of asphaltenes from various sources. Energy Fuels. 2000;14(3):677-84.

Habib FK, Diner C, Stryker JM, et al. Suppression of addition reactions during thermal cracking using hydrogen and sulfided iron catalyst. Energy Fuels. 2013;27(11):6637-45.

Hashemi R, Nassar NN, Pereira-Almao P. Transport behavior of multimetallic ultradispersed nanoparticles in an oil-sands-packed bed column at a high temperature and pressure. Energy Fuels. 2012;26(3):1645-55.

Hashemi R, Nassar NN, Pereira-Almao P. Enhanced heavy oil recovery by in situ prepared ultradispersed multimetallic nanoparticles: a study of hot fluid flooding for Athabasca bitumen recovery. Energy Fuels. 2013;27(4):2194-201.
Hashemi R, Nassar NN, Pereira-Almao P. In situ upgrading of athabasca bitumen using multimetallic ultra-dispersed nanocatalysts in an oil-sands-packed bed column: Part 1, produced liquid quality enhancement. Energy Fuels. 2014a;28(2):1338-50.

Hashemi R, Nassar NN, Pereira-Almao P. In situ upgrading of Athabasca bitumen using multimetallic ultradispersed nanocatalysts in an oil sands packed-bed column: Part 2, solid analysis and gaseous product distribution. Energy Fuels. 2014b;28(2):1351-61.

Hashemi R, Nassar NN, Pereira-Almao P. Nanoparticle technology for heavy oil in situ upgrading and recovery enhancement: opportunities and challenges. Appl Energy. 2014c;133:374-87.

Hosseinpour N, Mortazavi Y, Bahramian A, et al. Enhanced pyrolysis and oxidation of asphaltenes adsorbed onto transition metal oxides nanoparticles towards advanced in situ combustion EOR processes by nanotechnology. Appl Catal A. 2014;477:159-71.

IEA. Resources to Reserves 2013.

IEA. World Energy Investment Outlook. 2014.

James L, Rezaei N, Chatzis I. VAPEX, warm VAPEX and hybrid VAPEX: the state of enhanced oil recovery for in situ heavy oils in Canada. J Can Pet Technol. 2008;47(4):12-8.

Jiang S, Liu X, Liu Y, et al. editors. In Situ Upgrading Heavy Oil by Aquathermolytic Treatment Under Steam Injection Conditions. In: SPE international symposium on oilfield chemistry. Society of Petroleum Engineers; 2005.

Kapadia PR, Kallos M, Gates ID, editors. A comprehensive kinetic theory to model thermolysis aquathermolysis gasification combustion and oxidation of athabasca bitumen. In: SPE improved oil recovery symposium. Society of Petroleum Engineers; 2010.

Kumar J, Fusetti L, Corre B, editors. Modeling in-situ upgrading of extraheavy oils/tar sands by subsurface pyrolysis. In: Canadian unconventional resources conference. Society of Petroleum Engineers; 2011.

Luo P, Gu Y. Effects of asphaltene content on the heavy oil viscosity at different temperatures. Fuel. 2007;86(7):1069-78.

Luo P, Yang C, Gu Y. Enhanced solvent dissolution into in situ upgraded heavy oil under different pressures. Fluid Phase Equilib. 2007a;252(1):143-51.

Luo P, Yang C, Tharanivasan A, et al. In situ upgrading of heavy oil in a solvent-based heavy oil recovery process. J Can Pet Technol. 2007b;46(9):37-43.

Maity S, Ancheyta J, Marroquín G. Catalytic aquathermolysis used for viscosity reduction of heavy crude oils: a review. Energy Fuels. 2010;24(5):2809-16.

Monin J, Audibert A. Thermal cracking of heavy-oil/mineral matrix systems. SPE Reserv Eng. 1988;3(04):1243-50.

Montoya T, Coral D, Franco CA, et al. A novel solid-liquid equilibrium model for describing the adsorption of associating asphaltene molecules onto solid surfaces based on the "Chemical Theory". Energy Fuels. 2014;. doi:10.1021/ef501020d.

Moore R, Laureshen C, Mehta S, et al. A downhole catalytic upgrading process for heavy oil using in situ combustion. J Can Pet Technol. 1999;38(13):1-8.

Mousavi-Dehghani S, Riazi M, Vafaie-Sefti M, et al. An analysis of methods for determination of onsets of asphaltene phase separations. J Pet Sci Eng. 2004;42(2):145-56.

Mullins OC. The asphaltenes. Annu Rev Anal Chem. 2011;4: 393-418.

Mullins OC, Sabbah H, Jl Eyssautier, et al. Advances in asphaltene science and the Yen-Mullins model. Energy Fuels. 2012;26(7):3986-4003.

Nasr T, Beaulieu G, Golbeck H, et al. Novel expanding solventSAGD process ES-SAGD. J Can Pet Technol. 2003;42(1):13-6.

Nassar NN. Asphaltene adsorption onto alumina nanoparticles: kinetics and thermodynamic studies. Energy Fuels. 2010;24(8): 4116-22. doi:10.1021/ef100458g. 
Nassar NN, Hassan A, Pereira-Almao P. Application of nanotechnology for heavy oil upgrading: catalytic steam gasification/ cracking of asphaltenes. Energy Fuels. 2011a;25(4):1566-70.

Nassar NN, Hassan A, Pereira-Almao P. Comparative oxidation of adsorbed asphaltenes onto transition metal oxide nanoparticles. Colloids Surf, A. 2011b;384(1):145-9.

Nassar NN, Hassan A, Pereira-Almao P. Effect of surface acidity and basicity of aluminas on asphaltene adsorption and oxidation. J Colloid Interface Sci. 2011c;360(1):233-8.

Nassar NN, Hassan A, Pereira-Almao P. Effect of the particle size on asphaltene adsorption and catalytic oxidation onto alumina particles. Energy Fuels. 2011d;25(9):3961-5.

Nassar NN, Hassan A, Pereira-Almao P. Metal oxide nanoparticles for asphaltene adsorption and oxidation. Energy Fuels. 2011e;25(3):1017-23.

Nassar NN, Hassan A, Carbognani L, et al. Iron oxide nanoparticles for rapid adsorption and enhanced catalytic oxidation of thermally cracked asphaltenes. Fuel. 2012a;95:257-62.

Nassar NN, Hassan A, Pereira-Almao P. Thermogravimetric studies on catalytic effect of metal oxide nanoparticles on asphaltene pyrolysis under inert conditions. J Therm Anal Calorim. 2012b;110(3):1327-32.

Nassar NN, Hassan A, Luna G, et al. Comparative study on thermal cracking of Athabasca bitumen. J Therm Anal Calorim. 2013a; 114(2):465-72.

Nassar NN, Hassan A, Luna G, et al. Kinetics of the catalytic thermooxidation of asphaltenes at isothermal conditions on different metal oxide nanoparticle surfaces. Catal Today. 2013b;207: $127-32$.

Nassar NN, Hassan A, Vitale G. Comparing kinetics and mechanism of adsorption and thermo-oxidative decomposition of Athabasca asphaltenes onto $\mathrm{TiO}_{2}, \mathrm{ZrO}_{2}$, and $\mathrm{CeO}_{2}$ nanoparticles. Appl Catal A. 2014;484:161-71.

Nassar NN, Franco CA, Montoya T, et al. Effect of oxide support on $\mathrm{Ni}-\mathrm{Pd}$ bimetallic nanocatalysts for steam gasification of $n-\mathrm{C}_{7}$ asphaltenes. Fuel. 2015a;156:110-20.

Nassar NN, Betancur S, Acevedo S, et al. Development of a population balance model to describe the influence of shear and nanoparticles on the aggregation and fragmentation of asphaltene aggregates. Ind Eng Chem Res. 2015b;54(33):8201-11.

Opfermann J, Kaisersberger E. An advantageous variant of the OzawaFlynn-Wall analysis. Thermochim Acta. 1992;203:167-75.
Ozawa T. A new method of analyzing thermogravimetric data. Bulletin of the Chemical Society of Japan. 1965;38(11):1881-6.

Rooney JJ. Eyring transition-state theory and kinetics in catalysis. J Mol Catal A. 1995;96(1):L1-3.

Rosales S, Machín I, Sánchez M, et al. Theoretical modeling of molecular interactions of iron with asphaltenes from heavy crude oil. J Mol Catal A. 2006;246:146-53.

Sanford EC. Molecular approach to understanding residuum conversion. Ind Eng Chem Res. 1994;33(1):109-17.

Savage PE, Klein MT, Kukes SG. Asphaltene reaction pathways. 1. Thermolysis. Ind Eng Chem Process Des Dev. 1985;24(4): 1169-74.

Sestak J. Thermodynamical properties of solids. Prague: Academia; 1984.

Sheu EY, Shields MB, Storm DA. Viscosity of base-treated asphaltene solutions. Fuel. 1994;73(11):1766-71.

Siddiqui MN. Catalytic pyrolysis of Arab Heavy residue and effects on the chemistry of asphaltene. J Anal Appl Pyrol. 2010; 89(2):278-85.

Speight J. Thermal cracking of Athabasca bitumen, Athabasca asphaltenes, and Athabasca deasphalted heavy oil. Fuel. 1970;49(2):134-45.

Tedeschi M., editor. Reserves and production of heavy crude oil and natural bitumen. In: 13th world petroleum congress. World Petroleum Congress; 1991.

Trejo F, Rana MS, Ancheyta J. Thermogravimetric determination of coke from asphaltenes, resins and sediments and coking kinetics of heavy crude asphaltenes. Catal Today. 2010;150(3):272-8.

Vyazovkin S, Burnham AK, Criado JM, Pérez-Maqueda LA, et al. ICTAC Kinetics Committee recommendations for performing kinetic computations on thermal analysis data. Thermochim Acta. 2011;520(1):1-19.

Wargadalam VJ, Norinaga K, Iino M. Size and shape of a coal asphaltene studied by viscosity and diffusion coefficient measurements. Fuel. 2002;81(11):1403-7.

Wichert G, Okazawa N, Moore R, et al editors. In-situ upgrading of heavy oils by low-temperature oxidation in the presence of caustic additives. In: International heavy oil symposium; 1995.

$\mathrm{Xu} \mathrm{HH}$, Okazawa N, Moore R, et al. editors. In situ upgrading of heavy oil. In: Canadian international petroleum conference. Petroleum Society of Canada; 2000.

Young DA. Decomposition of solids. Oxford: Pergamon; 1966. 